\title{
El modelo aristocrático de la paideia antigua. La persistencia de la areté heroica
}

\author{
Marcos Santos Gómez. Universidad de Granada \\ Recepción: 14 de marzo de 2017 | Aceptado: 15 de diciembre de 2017 \\ Correspondencia: Marcos Santos | Correo-e: masantos@ugr.es
}

iD 0000-0002-7058-5177

Citar: Santos, M. (2017). El modelo aristocrático de la paideia antigua. La persistencia del areté heroica. ReiDoCrea, 6, 343-355.

\begin{abstract}
Resumen: En nuestro trabajo, que es de naturaleza y metodología fundamentalmente teórica aunque acude a lo histórico, pretendemos apuntar una posible interpretación del origen de la educación en Occidente. Ésta consiste en la idea de que la paideia griega, hasta la época clásica y posterior, ha consistido en una extrapolación de la cultura de la nobleza y sus valores heroicos relatada por los textos homéricos. Será la huella de este mundo y de estos textos lo que reaparecerá, bien para ser imitado y transfigurado, o bien para cuestionarse, incluso en el mundo del logos y de la democracia ateniense. Sin embargo, en este texto que presento no llegamos tan lejos y nos limitamos a señalar los rasgos de este universo heroico que en el siglo $\mathrm{V}$ a $\mathrm{C}$., en la Atenas democrática, sobre todo era motivo literario y pedagógico de los poemas de Píndaro. Asimismo, siglos antes, Hesíodo había tratado de ennoblecer el terrible mundo campesino, adaptando lo heroico de los poemas homéricos al mismo.
\end{abstract}

Palabras clave: Paideia | Educación Homérica

The Aristocratic Model of Ancient Paideia. Persistence of Heroic Areté

Abstract: In this article, which is fundamentally theoretical in nature and methodology although it refers back to the historical, we aim to present a possible interpretation of the origin of Western education. It consists of the idea that the Greek paideia, up to and after the classical period, has consisted of an extrapolation of the culture of the nobility and their heroic values as narrated by Homeric texts. It is the mark left by this world and these texts that will reappear, either to be imitated and transfigured, or to be questioned, even in the world of logos and Athenian democracy. However, in the present text we do not go so far but instead focus on pointing out the features of this heroic universe that in the fifth century B.C., in democratic Athens, especially, was the literary and pedagogical theme of the poems of Pindar. In the same way, years before, Hesiod had attempted to ennoble the terrible rural world, adapting the heroic of Homer's poems to this world.

Keywords: Paideia | Homeric Education

\section{Introducción: educación y metafísica en la cultura griega}

Menciona Werner Jaeger en la corta Introducción de su magnífica obra Paideia (1990) el principio que aplica a la hora de interpretar lo acaecido en Grecia entre los siglos VIII a IV a. C. Su idea motriz es la existencia de una estrecha interconexión entre la educación, la cultura y la política, ámbitos que se fueron transformando y racionalizando en la Grecia clásica como proceso propio del llamado "milagro griego". El logos griego emergente surgió imbricado a un nuevo ethos y a la polis, aunque su nacimiento ya se diera en la Grecia arcaica de terratenientes nobles y campesinos sometidos. Un logos que, junto a todo lo demás, se fue modelando, divergiendo y evolucionando durante unos pocos siglos al modo de distintas aproximaciones para captar la realidad y su "verdad". Pero lo más destacable de esta obra es la explicación de que la puesta en marcha de la racionalización de la relación del hombre con su cultura, con el conocimiento (mitos, religión, tradiciones heredadas de modos de vida anteriores), requirió la "complicidad" de una ingente tarea educativa entendida como una formación, como una revitalización y dinamización constante de los contenidos de 
la cultura que sólo podía ser obra de una pedagogía destinada, simultáneamente, a modelar el tipo de hombre que requería toda esta transformación y este nuevo modo de pensar el mundo. Estamos refiriéndonos a la creación, por medio de una empresa total educadora, de un sujeto capaz de plantearse de manera consciente su civilización y de desenvolverse en el mundo desde la relativa distancia respecto a sus saberes tradicionales. Porque la clave de la civilización griega clásica, para Jaeger, sobre todo estriba en un esfuerzo deliberado, y en su mayor parte consciente, de construir el tipo de hombre que correspondía con los cambios políticos que se estaban dando, que fuera al mismo tiempo objeto y sujeto, paciente y hacedor de estos procesos. En particular, el nuevo modo de pensamiento y esta pedagogía van emergiendo y activándose sobre todo en la literatura (que es la gran educadora, para Jaeger, de Grecia), donde se construye esta razón que podemos calificar como "pedagógica".

Se desarrolla, pues, una "producción" del nuevo hombre a la que subyace un modo de relación específico tanto con la existencia propia como con la de los demás, un modo de vida que es, a su vez, un modo político. Lo educativo existe porque hay una historicidad esencial que arraiga en lo más hondo de nuestro ser y que ha de "construirse" en los términos (provisionales) de una sociedad, de una época, de una biología, que se saben o presienten, sin embargo, destinados a desaparecer. Esta capacidad material y metafísica que tiene el hombre de hacerse conscientemente, tomando conciencia de ese mismo proceso por el que va llegando a ser, en permanente gerundio y por tanto compuesto de formas intermedias de realidad o existencia, de meras posibilidades, es lo que permite que seamos seres educandos, es decir, que nos podamos educar.

No se perderá de vista este carácter, propio de lo educativo, de estar hondamente arraigado en el ser, si mantenemos la perspectiva acerca de nuestra formación como algo "gerundivo" o, dicho en otros términos, histórico, que es otra forma de decir que nunca estamos acabados. Si el hombre concreto y personal, o un pueblo, es capaz de captar la tensión que nos constituye, el hueco o el vacío que es nuestra esencia, no cederemos a la fosilización de las construcciones que la cultura y la sociedad han hecho de nosotros, a su idolatría, sino que mantendrán su juego en relación con el existir en sí. Quizás pensar, hoy como en la Grecia clásica, sea ese modo de atisbar los abismos que nos cercan, los fantasmas que habitan las "interioridades" y su última vinculación con un ser que parece antes "nadear" lo que "toca" que "construirlo".

Esta reflexión que sitúa a la educación y a la pedagogía en el núcleo mismo de la cultura y del quehacer humano, en el centro del teatro de la vida, es muy vieja y ya existía en Grecia, porque los griegos pensaron el ser pensando quiénes eran. Al margen de sus derivaciones concretas, de tipo metafísico o platónico o los muchos matices de Aristóteles, la genialidad y la singularidad de este proceso fue que los helenos emprendieron una tarea en gran medida consciente y voluntaria de construir el tipo de hombre acorde con el mundo que querían. Para ello se sirvieron de lo que hoy llamaríamos "cultura" o "conocimiento" que en un proceso semejante a la Bildung alemana del siglo XIX y posterior, trataba de plasmar un ideal, de encarnarlo y realizarlo en cada hombre. Una construcción lúcida si no olvida su origen abisal en el peligro y la incertidumbre traídos al mundo por la nueva razón irónica, que supuso el esfuerzo deliberado con los materiales de los antiguos mitos, buscando, en el caso de Atenas, más allá de su despojo de contenidos y de la formalización de sus verdades y métodos (propios de la Grecia jónica), una reelaboración del propio hombre mediante la reelaboración de dichos contenidos y el esfuerzo hermenéutico por releerlos. Es decir, estamos ante un "uso" consciente de lo que ciega e inercialmente lo constituía a uno y constituía el propio mundo. Eso fue, señala Murray (2013), el origen de la gran tragedia de Esquilo, por ejemplo. Cuando la "construcción" se torna una labor lúcida, 
en este sentido, ya no es simple cristalización de la realidad que tornara invisible los abismos que nos ciernen, sino todo lo contrario, es puro contemplar cara a cara lo más hondo de la existencia. Así, para Lesky, la tragedia es hija de la racionalidad emergente propia de la Grecia posterior al siglo VIII a. C., hija, a fin de cuentas, de la lucidez, de la razón, del "dar cuenta de" y del logos que emergiera en Grecia (Lesky, 1970).

Jaeger (1990) matiza que esta labor constructiva o pedagógica fue política, porque todo, podemos añadir nosotros recordando a Aristóteles, en el animal político es político, viene teñido de política, es decir, de una necesaria forma comunitaria. Aunque hoy tendamos a interpretar la educación, cada vez más, como un aprendizaje individual, acaso de destrezas, y vayan relativizándose más el modo griego ático de pensar como un exprimir los contenidos culturales para sacar de ellos el tipo de hombre de, por ejemplo, la democracia ateniense, para adaptar la razón al logos comunitario y verbal de las asambleas, la verdad es que no hay, en efecto, educación (ya lo decía Hannah Arendt) sin el encuentro con el poso vivo de la cultura. Somos a partir de lo que hay, de lo que hallamos al nacer y de lo que nos encuentra. La educación empieza por ser la transmisión de una forma concreta de ser el hombre, de su "naturaleza" que se hace efectiva en el modo de relación y de vínculos que vamos entablando a lo largo de este proceso. Esta pedagogía o construcción regulada del sujeto de, en el caso ateniense, la democracia, presupone un cierto orden, un cosmos, que es el gran paradigma común a los griegos. El mundo es reajustable, re-ordenable, puede seguir un cierto plan y por eso la contemplación consciente que la cultura hace de sí misma en la Grecia clásica (en la labor ingente de hermenéutica ilustrada de los propios mitos que ya está presente en los mitógrafos Homero y Hesíodo) es posible, su sopeso en relación con la legalidad que se presupone rige y vertebra a la naturaleza, que emana del propio ser.

Hay aquí uno de los contenidos claves de la civilización griega que coexiste, como es sabido, con la tensión que lo amenaza constantemente, en el modo del arte o la religión dionisiaca, que son acaso manifestaciones de que el pincel que dota de orden al mundo, que identifica su orden o acaso lo fabrica, puede estar, por otro lado, desmembrándolo. Es esa fuerza erosiva, en un sentido amplio, y en cuanto a hermenéutica del hombre y de la realidad que ha de empezar siendo una hermenéutica de la cultura (en los mencionados mitógrafos), la otra cara de la moneda del llamado milagro griego. Una razón cósmica, que ordena y presupone un orden en el mundo al cual adecuar la sociedad y la "naturaleza" humana. Sin embargo, es obvio que lo apolíneo, el corsé que requiere el mundo para comprenderlo, multiplica las fuerzas y tensiones de un mundo que para recuperar su verdadero equilibrio tendría que dejado ser caótico. Quizás una forma metafísica de entender lo que en los términos mucho más superficialmente positivistas aludía Freud con el malestar de la cultura, o precio de frustración que el hombre ha de pagar para civilizarse. Según esto, a la educación le acompañaría un ineluctable malestar y por tanto la constante amenaza de ceder a lo oceánico.

"Como si la identidad griega estuviera empeñada en un juego de apropiación de un horizonte incesantemente suplantado por otro que lo estira desde sus márgenes de ignorancia. De Homero a Platón el hombre griego es un continuo irrealizable; cada vez que cree poseerse se deshace en nuevas exigencias; entonces se prolonga indefinidamente, se hace inalcanzable" (Lorite, 1985, 82). Y en efecto, Grecia nos conduce a suponer que heredamos, junto con la gozosa posibilidad de crearnos siempre de nuevo, un viejo malestar, una serie de tensiones, de carencias o de traumas. Hay también una serie de posibilidades truncadas y de negatividades que siguen amenazando hoy a toda lucidez que trate de enfrentarse conscientemente con su cultura. Lo curioso y resaltable, si mantenemos el vínculo paradójico del tener que 
construirse con la lucidez de saberse o presentirse nada, es que cuando uno emprenda de manera consciente su construcción ya esté, de manera amenazante, introduciendo la posibilidad de que todo, absolutamente todo, acabe viniéndose abajo.

\section{Arqueología de la paideia: la areté como distinción y cualidad de la nobleza en la Grecia homérica.}

El libro recientemente publicado en español de Bowra sobre Homero lo estudia como un mitógrafo, es decir, como alguien (de cuya existencia no duda ni de que fuera una única persona) que fijó o por lo menos recogió y sistematizó y compiló una tradición oral sobre la religión y los mitos. En su caso, al parecer, aunque fijó el texto, Bowra habla más bien de la tradición oral en torno a las leyendas que relata y que en cualquier caso quedaron tal como hoy las conocemos y como las cultivara Grecia y las posteridad, en el siglo VIII a. C.

Homero se refería en gran parte a unos mitos heroicos de un mundo que, señala nuestro autor, cultivaba los valores y era transmitido por la educación entre la clase de guerreros que en su época, en el siglo VIII, y en los restos que habían llegado del mundo micénico muy anterior, constituían la clase gobernante. Era un mundo, el del siglo VIII, ya no tanto de reyes, cuyas monarquías de tipo micénico habían entrado en decadencia, sino de una casta de señores que vivían en palacios rurales, en un contexto de casas y granjas en el campo que prácticamente no era todavía el universo urbano de las ciudades estado posteriores, y que vivían de sus tierras y de los botines de guerra y el pillaje.

Así que estos señores, como los pretendientes que retrata la Odisea que demandan a Penélope en matrimonio en la larga ausencia de Ulises en la isla de Ítaca, ocupaban grandes fincas rurales, con numerosísimos esclavos y empleados (muchos menos que en época micénica), que junto con el ejército y las profesiones especializadas, constituían la sociedad y la economía de la época en Grecia. En Jonia podía haber influencias algo diferentes de tipo asiático, pero en la Grecia europea, el tipo de mundo del siglo VIII era éste. Aunque los textos homéricos se estudiarían en las escuelas y en los centros cultivados de la Grecia posterior urbana e ilustrada, justificándose por su valor educativo, lo cierto es que, según matiza Bowra, no fueron textos para educar masivamente a los griegos, sino a esa pequeña parte que constituía la élite, al menos cuando fueron escritos. Ellos, los señores, sí verían retratados y ensalzados los modelos que trataban de regir su comportamiento, el del mundo heroico. Un mundo que Jaeger (1990) dirá que se extrapolará, sin embargo, al nuevo mundo y a las clases nuevas que cultivarán el heroísmo en el siglo $\mathrm{V}$ tanto en la escultura como en el deporte. El deporte, de hecho, de gran prestigio y valor educativo para la Grecia clásica, será un remedo del mundo heroico de la antigua nobleza del siglo VIII e incluso micénica. Esto sustenta la idea de que la educación clásica tendría su más primario y antiguo modelo en el mundo de la aristocracia. El conocimiento acabaría siendo una suerte de gimnasia para el espíritu y la educación deportiva sería el intento de regular el cuerpo para lograr esa vieja y envidiada excelencia del mundo heroico, para encarnar la virtud que ya no sería de la sangre, sino que sería el producto de la voluntad por adquirirla y del esfuerzo. Es, sin duda, lo que da origen a la pedagogía y lo que todavía hoy la caracteriza. Se trataría de emular a una aristocracia que era admirada y vagamente recordada, en el contexto de las polis, siendo tan solo realmente el modelo espartano el que habría logrado la plena "democratización" de este ideal de la sangre noble.

El texto de la llíada es en sí un texto tan arcaico como rico y mejorado en relación con la épica anterior y la muy posterior que se ha cultivado, también en la forma de 
grandes poemas, en distintas culturas (Gilgamesh). Su conocido tipo de verso, el hexámetro dactílico, es, dice Bowra, una específica invención griega, que copiarían los romanos, a partir de la métrica cuantitativa propia de las viejas lenguas indoeuropeas, basada en la alternancia de pies compuestos por un determinado orden de sílabas largas y breves (que en nuestras lenguas actuales se ha sustituido por otros modos de la repetición o la simetría que está en la base de toda poesía, incluido el verso libre). La poesía pretende musicalizar el lenguaje, para dotarlo de mayor potencia expresiva y dar densidad a sus partes. El lenguaje se concentra en su forma para que ésta sea parte activa en la expresión del contenido. En este sentido la poesía, también hoy, intenta reforzar o revitalizar el lenguaje, convertirlo en un instrumento expresivo más capaz y potente para designar elementos de la realidad. Se intenta depurar nuestro modo de acceso a la verdad, podríamos afirmar en este sentido, la fuerza denotativa del lenguaje a través de lo connotativo. "La métrica era mucho más importante para los griegos de que es para nosotros (...). Querían poner en su poesía una medida equilibrada que respondiera a otra medida, una correspondencia sagazmente buscada de significado y ritmo; les gustaba una gran extensión de movimiento variado, suave y poderoso, y, sin embargo, al mismo tiempo, absolutamente controlado" $(2002,83)$.

Pues en tiempos de Homero esta musicalización de la palabra de gran fuerza persuasiva la llevaban a cabo los aedos. La poesía, como la mayor parte del texto de las tragedias, se cantaba y se cultivaba además una tradición musical muy elaborada y compleja de la que, por no escribirse, no nos ha llegado absolutamente nada. Esto era así en los tiempos de Homero, que con estos recursos embellecía fundamentalmente la guerra y el heroísmo. En la cultura del héroe, por ejemplo, se entiende la famosa "cólera de Aquiles" que era producto de un serio agravio infligido a los códigos de la moral consuetudinaria, no escrita, y las leyes que regían las relaciones entre héroes y entre su remedo mundano, los nobles. Se ensalzaba, pues, un honor y los modos de restituirlo en el que el mundo guerrero fundaba su conducta y sus relaciones, sus pactos y sus reconciliaciones, evitándose el excesivo derramamiento de sangre y las venganzas demasiado cruentas. Homero, de hecho, es bastante realista y toma elementos de, no sólo la tradición, sino del mundo que tenía ante sus ojos y del que podemos saber algo por pasajes tan elocuentes como la famosa descripción del escudo de Aquiles representando escenas corrientes de la vida de entonces (marcadísima, por cierto, por el pillaje y la guerra). Como dato curioso, la escritura apenas existe en la sociedad y periodo que nos pinta Homero (la llamada Edad oscura de Grecia, entre el desusado alfabeto micénico y la invención del actual alfabeto griego).

Pues bien, en relación con la influencia de esta cultura de la época heroica de la nobleza, incidirá en la paideia, influyendo su desarrollo en un sentido divergente y, a menudo, convergente. En este sentido, Jaeger, afirma: "La educación no es otra cosa que la forma aristocrática, progresivamente espiritualizada, de una nación" (Jaeger, $1990,20)$. Según su idea, la educación, que siempre es formación o paideia o Bildung (Vilanou, 2001), reproduce el esquema de la sociedad arcaica en la que un sector minoritario de la amplia población se erigía en portador de una cualidad que lo distinguía del resto y que para que fuera tal, es decir, para que dicha cualidad conservara su aura, debía preservarse del dominio de la mayoría. Esto casi es una de las dinámicas que la sociedad establece y reproduce en torno a lo que Bourdieu llamaba el "capital cultural", dentro del cual el conocimiento cultivado, guardado y transmitido en la academia (escuela y universidad, que sin embargo lo desnaturalizan y, por tanto, sólo forma realmente parte, como capital, de quien ha sido socializado en él fuera de la academia), de enorme "valor simbólico", es el que garantiza el selecto acceso a las claves que interpretan (o gobiernan) la realidad. Es decir, el hombre, que es animal político y social, todo lo mira social y políticamente, filtrado o teñido por una ideología que habita en un modo particular de mundo social y político. Quizás es lo 
que presupone Jaeger que, de un modo amplio, sostiene que el mundo nacido del "milagro" griego se caracteriza por la hermenéutica crítica que va realizando de su propio contenido cultural, sin que dentro de la red de explicaciones o interpretaciones reelaboradas, pueda trascenderse a sí mismo (en un mundo que mantuvo siempre el esclavismo, por ejemplo, se hablaba de la igualdad esencial de los hombres, por parte de los estoicos, o de la participación de todos en la miseria y el sufrimiento de las víctimas cuyo sacrificio nos ha dado la vida en el famoso discurso fúnebre de Pericles a los atenienses, transcrito por Tucídides).

Esta ideología, manteniéndonos solamente en el periodo estudiado por Jaeger, es la que aparece en la llíada y la Odisea de Homero, obras que la presentan y ya la propugnan como modo de pensar el mundo. Lo que estos poemas épicos, que fundan de algún modo Occidente, pretenden es educar en una areté o ideal o virtud (entiendo aquí por areté o virtus la encarnación de un ideal, en este caso, nobiliario y guerrero) (Ramos de Souza, 2007, 200) que mantiene algo de eso siempre incluso a través de sus transformaciones más insólitas, como la que se dará en la cueva del solitario anacoreta o ermitaño muchos siglos después. El conocimiento, pues, se entiende al modo de lo selecto, lo escogido y lo privilegiado que establece, por tanto, una mirada que realza claves más o menos secretas, no públicas, de la realidad a costa de disminuir esa misma realidad o su apariencia. "La paideia griega estaba basada en el conocimiento y aprendizaje de las costumbres ancestrales que permitían dar a los jóvenes (a los ciudadanos, se entiende) la instrucción a través de la cual aprendían a rehuir las acciones malas o vergonzosas, inculcándose el deseo de lo noble y excelente" (Pérez Miranda, 2009, 241). Una trasposición al plano de lo ideológico de lo que ocurría en el mundo donde una escogida aristocracia debía justificarse socialmente. La cultura, así, se escindió, quedándose para esa clase lo más profundo, lo más real, lo envidiado y arduamente aprendido por quienes se iniciaban en el manejo y gobierno de la sociedad.

Jaeger no se amedrenta lo más mínimo al probar su intuición sobre la perduración de uno de los clichés más arraigados y primitivos en nuestra civilización, precisamente en los ámbitos más refinados de la misma, donde como en un espejo, se reflejan y duplican cansinamente. Asevera de manera muy certera que "El pensamiento ético de Platón y de Aristóteles se funda en muchos puntos, en la ética aristocrática de la Grecia arcaica" (Jaeger, 1990, 27). De hecho, la naciente filosofía surge como conocimiento al que se accedía de manera costosa mediante el consejo constante y la dirección espiritual, como refleja la Odisea en pasajes muy significativos (Jaeger, $1990,35)$. Es decir, mediante una educación cuasi dirigida, en un sentido cercano al actual aunque todavía muy primitivo. Así lo afirma Jaeger: "La educación, considerada como la formación de la personalidad humana mediante el consejo constante y la dirección espiritual, es una característica típica de la nobleza de todos los tiempos y pueblos. Sólo esta clase puede aspirar a la formación de la personalidad humana en su totalidad; lo cual no puede lograrse sin el cultivo consciente de determinadas cualidades fundamentales" (Jaeger, 1990, 35). Esto exige una regulación (recordemos la palabra latina que nos da la clave de la pedagogía medieval universitaria: regula). Es decir, surge, acaso por vez primera, el ideal formativo, la formación como manera de educarse a través de una metódica y ardua encarnación del ideal de una cultura, que constituye lo que hemos llamado areté, que en la lliada es heroica y en la Odisea, en determinados pasajes que Jaeger asocia con el magisterio de una mujer en el héroe, alude a una belleza que se va a definir como valiosa por sí misma, en un plano diferente del de la utilidad o la guerra, y que tiene que ver con los paisajes, con las descripciones hermosamente elaboradas y con el lenguaje refinado.

Todo ello, en sendos poemas épicos, aparece como "material educativo" que emplea el paradigma $\mathrm{o}$ el ejemplo como método que pretende plasmar honda y 
sentimentalmente el ideal para que cobre vida en el hombre noble de aquel mundo arcaico que era educado consciente y tenazmente para ello, dentro del grupo reducido de su clase social. Se trata, como hemos dicho, de una regulación de la conciencia del hombre que aprende a ser como es requerido por la cultura y en la que ya se abren paso esquemas u subesquemas que van a sostener una longeva vigencia en la educación y la cultura occidental, como son algunos pasajes en los que se va derivando un pensamiento más analítico que pretende superar y mirar con neutralidad las propias pasiones que suelen ir en dirección opuesta (jasunto recurrente que logrará cierta conciliación en el ideal estoico tardío, de Séneca, siglos después). Resalta Jaeger la llamada Telemaquia, o relato de la "educación" de Telémaco para convertirlo en alguien selecto, en un alma refinada. Sin estar, advierte, con una novela de formación o pedagógica al estilo moderno, desde luego, tenemos ya los elementos básicos de la naciente pedagogía que los griegos estaban inventando: la constitución de un "corazón" y una conciencia, es decir, de un modo concreto de ser hombre, un tipo de hombre que precisa ser fabricado más allá de los procesos más "naturales" de la socialización.

Aunque hay que resaltar que esta proto-educación, en el contexto de aquel mundo primitivo, es presentada como algo inútil que no funciona si no existe en el educando la sangre noble, como si la areté mantuviera un elemento imponderable y sagrado, un origen divino. No muy lejos, por cierto, del ideal sacerdotal del monje o clérigo escolástico que ha dedicado su vida religiosamente al conocimiento, pero que los recibe sacramentalmente. La nobleza se irá convirtiendo en una nobleza del espíritu, con la educación cristiana, y en la universidad medieval, que será, junto con la Iglesia, su producto más avanzado, que se constituirá en templo del saber.

De manera muy digna de anotarse, incluso precisa Jaeger, aproximándose a la impresión de que en la epistemología y en la metafísica perdura la ética aristocrática en muchos casos, lo siguiente: "Y si se considera que, en último término, la estructura íntima del pensamiento de Platón es, en su totalidad, paradigmática y que caracteriza a sus ideas como 'paradigmas fundados en lo que es', resultará perfectamente claro el origen de esta forma de pensamiento. Se verá también que la idea filosófica de 'bien', - más estrictamente del agathon, este 'modelo' de validez universal procede directamente de la idea de modelo de la ética de la areté propia de la antigua nobleza" (Jaeger, 1990, 47). Para añadir, en el mismo párrafo, la importante precisión de que "El desarrollo de las formas espirituales de la educación noble, reflejada en Homero, hasta la filosofía de Platón, a través de Píndaro, es absolutamente orgánica, permanente y necesaria. No es una 'evolución' en el sentido seminaturalista que acostumbra a emplear la investigación histórica, sino un desarrollo esencial de una forma originaria del espíritu griego, que permanece idéntico a sí mismo, en su estructura fundamental, a través de todas las fases de su historia" (Jaeger, 1990, 47).

Homero nos conduce también a la pregunta acerca de cómo puede un poema ser educativo, y desde luego Jaeger se apresura a puntualizar, por si no había quedado claro, hacia el final de su análisis de la educación homérica, que no tiene nada que ver con la fábula o la poesía moralista. Porque lo educativo no se dirige a proporcionar ningún barniz, salvo que dicho barniz forme parte de la afirmación de un tipo de mundo y de sujeto caracterizados, tal vez, por la escisión de un conocimiento desnaturalizado, escisión que también subyace en la vana erudición o la pedantería. Es algo mucho más serio y profundo. Lo que hace de la poesía épica de Homero una pedagogía es su conexión con la esfera más íntima, señala (Jaeger, 1990, 49) del ser humano, del tener que hacerse, de manera que aliente un ethos que sea plasmación del ideal, o modo de ser, específico de una civilización. De la poesía emana un deber pero porque arraiga en la más honda necesidad de sentido que tenemos los hombres. No es, pues, ni moraleja o sermón, ni presentación de un simple fragmento de realidad, sino 
conexión con esa necesidad profunda de tener que hacernos y de elegir o asumir una forma específica de estar en el mundo y de ser hombre.

Tanto la poesía "educativa" como la acción más actual y modernamente pedagógica participan de este rasgo de creación de realidad, de valoración y afirmación "ejemplar" de un modo de vida particular. Esto lo hace mejor la poesía que el pensamiento sistemático, que el logos discursivo, porque plasma imágenes entre la pura fluidez inasible de la vida y la distancia contemplativa del logos. Es más logos que la vida y más vital que el logos, expresa con gran acierto nuestro autor (Jaeger, 1990, 50). Así, más allá que constituirse en un reflejo de un mundo de caballeros y proezas propio de una sociedad arcaica y primitiva, lo que se muestra tiene, apunta Jaeger, una cierta vigencia universal, pues toca una de esas fibras que movilizan al oyente y conectan con algo esencial. Así lo sintetiza: "El pathos del alto destino heroico del hombre es el aliento espiritual de la llíada. El ethos de la cultura y de la moral aristocráticas halla el poema de su vida en la Odisea" (Jaeger, 1990, 51-52). Esto que es mito, y por tanto no estamos todavía en el intento consciente de normativizar de forma expresa y configurar al hombre que "quería" Atenas o Jonia. Se trata de un lenguaje mítico que, como todos los mitos, ejerce una función educadora aun cuando no se lo proponga, pues impresionan y lanzan a la acción. Son cantos públicos e idealizadores cuya herencia recogerán más tarde las tragedias. "Y si consideramos que las formas de prosa literaria que tuvieron una acción educadora más eficaz, es decir, la historia y la filosofía, nacieron y se desarrollaron directamente de la discusión de las ideas relativas a la concepción del mundo contenidas en la épica, podremos afirmar, sin más, que la épica es la raíz de toda educación superior en Grecia" (Jaeger, 1990, 55). En los poemas homéricos hay, en este sentido, y aunque no sean textos discursivos ni filosóficos, una interpretación creadora de la tradición, que es reconsiderada dentro del propio relato, y por tanto el germen, a pesar de todo, de una cierta conciencia filosófica. Hay una lucidez todavía dentro de un plano imaginativo, en la poesía que reverbera sobre sí misma.

Los poemas de Homero presentan las consecuencias del modo de ser heroico, sus vertientes existenciales, su carácter de respuesta o de intento de respuesta a las grandes preguntas del hombre y la propuesta de una forma de vida como su resolución, como un modo de ser hombre. Este modo "heroico" estriba en la aceptación de la propia misión, con sus peligros y sacrificios, en una vida consagrada a la muerte, en la elección deliberada de un destino peligroso. Todo lo cual reposa no sobre un mero deber o convención moral, sino en la normatividad que emana del ser de la realidad, de la íntima, terrible pero justa legalidad que vertebra lo que existe. El paradigma de un ser que impone su legalidad y que fluye, dotando de un orden, a menudo incomprensible, pero orden, al mundo (Jaeger, 1990, 61). Es decir, a pesar del torrente de pasiones propio de estos poemas homéricos, de su exaltación e hybris, de su pathos, hay un dique que podríamos tildar, hasta cierto punto, de racionalidad, una incipiente forma de racionalidad o de pretensión reguladora, en cuanto visión ordenada del universo. Se trata de que en lo que hace o siente el hombre existe una estrecha conexión con lo divino (esta es, creo, la intuición básica de cualquier mito pero que al escribirse comienzan a pensarse, independientemente de que Sócrates pretenda posteriormente la liberación del pensamiento de la escritura) y por tanto, nuestro modo humano de vida arraiga en algo mayor que lo dota de su razón y de su dignidad. $Y$ esto es ya, señala Jaeger, una anticipación del saber filosófico: "La intervención de los dioses en los hechos y los sufrimientos humanos obliga al poeta griego a considerar siempre las acciones y el destino humanos en su significación absoluta, a subordinarlos a la conexión universal del mundo y a estimarlos de acuerdo con las más altas normas religiosas y morales" (Jaeger, 1990, 63). 


\section{La "nobleza" de la vida campesina como areté en la poesía-pedagogía de Hesíodo}

Hesíodo ofrece la otra cara "cultural" de la moneda que era la sociedad de la Grecia arcaica (del siglo VIII a. C. y anterior) de nobles guerreros, por un lado, y campesinos, por otro lado, y en la medida en que estos últimos habían logrado una cierta autonomía como clase. Lo interesante y más relevante a mi juicio son dos aspectos. El primero es la corroboración por parte de Jaeger (1990) de que Hesíodo, que idea una paidea para el campesino, absorbe sin embargo la poderosa tradición e imágenes de los poemas homéricos, que aunque ya no pueden representar literalmente los valores que necesitaba y de los que vivía, en realidad, el campesino, aportan un cierto tono y lenguaje que sí necesita y de los que tiene que echar mano. Es decir, el movimiento ascendente, sublimador y que aspiraba a una cierta trascendencia en relación con la vida corriente, necesario para pensar su vida campesina, lo representaba el sello de lo aristocrático. Lo noble y egregio, en la visión homérica del mundo, les aportó el espacio en el que superar la opresión y estrechez de su dura vida y poder, de algún modo, aspirar a una cierta forma de libertad.

El ámbito de lo artístico, de lo poético, pues, que respondía a su propio mundo dividido, les ofrecía, en una aparente paradoja, como elemento propio sus categorías y el lenguaje preciso y claro con el que describirse y pensarse. Es interesante ver en tiempos tan lejanos y, en muchos aspectos todavía tan primitivos (a uno o dos siglos del denominado por Jaspers "tiempo eje", en torno al siglo VII a. C.), algunos de los movimientos básicos con los que se iniciaría el pensamiento como actividad de la consciencia que extraña y que sólo veremos propiamente, según Jaeger, con la más temprana sofística en el siglo V a. C. "En Grecia no se pretenden eruditos. La Sofística -en todo lo que tiene de descubrimiento del valor educativo- aspira a una cosa mucho más ambiciosa: a que sus estudiantes sean hombres libres, a que sepan gobernarse a sí mismos dominando sus pasiones y llevando la razón hasta sus más elevadas capacidades. Es decir, su proyecto se traduce en el deseo de formar aristoi, de donde se deriva la palabra aristócrata, hombres llenos de areté, término que nosotros solemos traducir por virtud, fuerza, capacidad" (Aranguren, 2004, 35). Un tratar de mirarse en el espejo de un mundo sublime propio de una clase "sublime", para desde un cierto ideal lejano, transmitir su halo a la vida atroz. Una superación de la propia vileza, en cuanto apego brutal al sacrificio de la tierra en aquellos tiempos, que, justamente por ser ya casi pensamiento y no mero pasatiempo evasivo, llena las categorías de lo noble con el contenido, con la materia que debe ser pensada. Así, Hesíodo mira el mundo campesino desde el prisma de lo singular, de lo aparte, para, y este es el segundo aspecto, ennoblecerlo, de algún modo, es decir, regularlo, dotarlo de razón.

Esta racionalidad ya la halla Hesíodo, también, en Homero y el mundo homérico de la incesante y total causalidad por la que en la realidad las cosas se engendran unas a otras para diferenciarse y establecer una cierta estructura en la vida que tiende al abandono y la disolución. Será pues una dignidad de procedencia noble, la que para Hesíodo es racionalización de la propia clase, dotarla de conexión con el centro mismo de la realidad y con el ser griego que fundamentalmente emana organización (cosmos). Pero además, la vida ordenada, es ya vida noble, fuente y expresión de una areté cuya procedencia sí es específicamente campesina y no aristocrática (Jaeger, 1990, 70-71). Una areté que lo es en cuanto aura noble, en cuanto algo dotado de prestigio y exclusividad que distingue a quien la porta, pero cuyo contenido, cuya materia, es la vida rural de quien trabaja hasta la extenuación en la tierra para asegurarse el sustento diario. 
Aparte de explicaciones sociológicas o historiográficas de estos procesos, que las hay muchas y muy certeras, interesa que destaquemos lo que el desarrollo del libro Paideia (1990) va sugiriendo principalmente, consistente en que el nivel del pensamiento está obviamente conectado con estos procesos sociológicos e históricos pero empieza a gozar de cierta autonomía, en la que una clase, como la campesina, comienza a fundar y realizar su libertad: "El conocimiento de la poesía homérica no significa sólo para los hombres del mundo hesiódico un enriquecimiento enorme de los medios de expresión. A pesar de su espíritu heroico y patético, tan ajeno al estilo de su vida, les ofrecía también, por la precisión y claridad con que expresaba los más altos problemas de la vida humana, el camino espiritual que los llevaba desde la opresora estrechez de su dura existencia, a la atmósfera más alta y más libre del pensamiento" (Jaeger, 1990, 70). Como hemos considerado, la grandeza de Homero son los tipos esenciales e imágenes con las que plasma "verdades" acerca de la humana existencia y son estos mismos tipos, nacidos en un movimiento ascendente, los que tiran, creo, para que el hombre "simple" piense su modo de vida y lo vincule con aspectos esenciales de la existencia.

No son ya poderosas imágenes las de Los trabajos y los días, pero sí es una vida laboriosa dignificada, a la que se infunde vigor y se eleva, en un segundo movimiento ascendente, a la esfera de lo exclusivo, de lo grande, de lo que irradia su magnificencia. Pensar, así, para Hesíodo es pintar de ideal lo cotidiano, hacerlo ideal. Cuando se desarrolle propiamente un pensamiento y una pedagogía consciente, con los sofistas en la Atenas del siglo $\mathrm{V}$ a. $\mathrm{C}$., este movimiento habrá conducido a una cierta racionalidad despojada de verdad, que ha relativizado el mundo y lo ha individualizado saboteándolo, habiéndose partido desde la búsqueda y distinción de una nobleza en el mismo que ahora, en la total dispersión sofística faltará, y que Platón reintroducirá en el movimiento del pensar. Una nobleza que, como esquema epistemológico y metafísico, introduce el juego de la trascendencia. Este juego circular es mencionado, casi tal cual, por Jaeger y lo consideraremos con más detenimiento al tratar el giro humanista, por poner lo cotidiano (los hombres) en el centro y dar la espalda a un cierto espejo embellecedor que lo torne exclusivo. Así, el más puro y terrenal humanismo de la sofística será el pensamiento despojado de su aura y que, paradójicamente, acabará cumpliendo una función social próxima al poder de una nueva nobleza social, la de los demagogos en las asambleas, o aristócratas de la palabra. Un pensamiento que renuncia a situarse en el punto arquimédico de la "verdad", pero que continúa su inercia. Al especializarse y formalizarse la paideia, que como tal, comienza verdaderamente entonces, esta dispersión social democrática individualista vuelve al elitismo, se torna exclusiva.

Este ideal que ofrece una imagen nueva y ejemplar de la vida, para la sociedad campesina, será, y esto es un tercer aspecto que quiero destacar: el derecho. El derecho es, para Hesíodo, lo que puede elevar la vida, dignificarla o, en la concepción estricta y literal del poeta, hacer que reine diké, la justicia. Es sabido que una de las primeras formas de racionalización de la sociedad que existe es el derecho y que éste era valorado como algo sagrado que, igual que las prescripciones rituales y los sacrificios, atraía lo divino (en lo que se habían concentrado los elementos hieráticos de la cultura aristocrática primitiva). Servía, en el imaginario quizás más profundo, para esa tarea de ennoblecimiento de la vida que acabaría siendo igual a la racionalización del hombre y de la sociedad por parte de una paideia consciente, meditada y regulada. Hesíodo funde derecho y trabajo como incipiente primer paso de esta racionalidad que Grecia, más o menos, inventaría. Es aquí donde se dan elementos entre lo noble y lo plebeyo, en un juego que va de uno a otro, parece, como el tan helénico elogio de la moderación (en la riqueza y las posesiones) que quiere establecer la prudente distancia respecto a las cosas y que alberga y aspira esta idea de la razón como 
mediadora, como una cierta nivelación del mundo frente a la hybris heroica y que sí es propiamente del campesino.

Del mundo homérico, sin embargo, no pudo Hesíodo extraer un elemento fundamental que, como conclusión tras el agotador trabajo pedagógico de la Telemaquia en la Odisea, es la nobleza de la sangre, innata, la areté como don que no es posible, por tanto, invocar mediante la educación. Hesíodo manifiesta precisamente su ideal, lo contrario, que la verdadera areté se busca y se consigue mediante la enseñanza y el humilde aprendizaje. Esto, podíamos aseverar, funda la pedagogía y la educación en un sentido ya más próximo y actual. Se está preparando el terreno para una paideia. En realidad, hay un prurito aristocrático, lo sigue habiendo, sólo que ahora estriba en conectarse con el centro irradiante de lo noble. Pero esto es ya, en una suerte de abstracción y sublimación, el orden que impera, que rige en lo más esencial al mundo. Y cuando la vida del campesino se manifiesta como ese orden, acorde con el mismo, entonces aparece una nueva nobleza en el mundo, la autoconciencia y el prestigio de una nueva clase social en la historia que deja de ser una civilización muda. Es esta pedagogía la obra que se plantea Hesíodo, mucho más profundamente que la de una simple poesía didáctica, la de la construcción de un nuevo mundo justo. El poeta, ahora, se introduce, interpreta y eleva las cosas cotidianas, extrayendo su sentido oculto, su sangre discretamente noble. Aparece, pues, la verdad, por primera vez en la poesía, y la misión educadora, constructora, del poeta que la invoca (Ramos de Souza, 2007, 196).

\section{Una educación que busca lo distintivo. La poesía de Teognis y Píndaro como educación "selecta" y perduración reaccionaria del modelo aristocrático en la Grecia de la democracia}

La perduración del ideal aristocrático, en medio de cambios sociales e históricos conducentes a modelos políticos diferentes e incluso opuestos, se da, con mayor o menor disimulo, en asuntos como la "perfección", el ideal educativo al que aspira la paideia y que aparece en la poesía. Píndaro y Teognis son un exponente de la fortaleza de este ideal que sobrevive y reverbera en el magnetismo y la bella musicalidad de los versos. Como ya dijimos, la primera educadora en Grecia, donde por primera vez podemos rastrear la paideia, es la poesía. Si la paideia trata de plasmar un ideal y encarnarlo, fabricando así un modo de ser hombre, la poesía se alza con una fuerza persuasiva ejemplar, herencia de las imágenes y recursos de la cultura mítica y por tanto capaz de remover hondamente a los hombres, de rehacerlos "desde dentro". En realidad, puntualiza Jaeger, estos poetas, en oposición al final definitivo del mundo que cantan, que datamos en el siglo $\mathrm{V}$ a. C., fueron recitados especialmente en ambientes selectos, en círculos aristocráticos.

Resulta imposible que los poetas, como Teognis, eludan el tiempo en que viven y emerge en ellos un individualismo propio del nuevo mundo naciente de "burgueses" y de la democracia, paralelo al poder disolvente de un logos obstinado que amenaza con derruir aquello que él mismo trata de construir. El nuevo mundo es incierto y se hace de singularidades, de individuos, a los que dirigir el proceso ya semiconsciente de la nueva paideia.

Teognis transmite preceptos heredados de la tradición y pertenecientes a la sabiduría de una clase noble. Su moral, su estética, su "paideia". Los escribe para fijarlos, pues muchos pertenecían a usos y costumbres orales, entre los cuales ya aparece, ligada a la educación, la fuerza de un eros que ha de presidirla, que la motiva y mueve. Se trata, en un principio, del eros propio de la relación de admiración y magisterio entre guerreros nobles y los jóvenes que se forman para serlo. Se persigue y ama, sobre 
todo, un ideal o areté, un cierto esplendor en lo que no abunda y luce de modo exclusivo. Un halo de distinción que siempre había acompañado al noble que así funda y reivindica su privilegio, como todavía hoy, en nuestras sociedades, puede verse que acompaña a las situaciones de privilegio social y a las relaciones de admiración-envidia-resentimiento entre clases sociales. Es esta areté que conmueve y emociona la que educa, la que fuerza a imprimir el modelo de hombre que la acompaña. Obra aquí, por tanto, una seducción cuyo prestigio todavía el nuevo logos no ha ido desmenuzando ni poniendo en evidencia. Pero se trata de una solemnidad que irradia y deslumbra que, sugiero, no va a desaparecer nunca de las relaciones educativas humanas tal como se irán ya dando después del "milagro griego". Un extremo que se opone, culturalmente, a la moderación como virtud que acompañará la preeminencia de la nueva clase emergente campesina y a las tiranías. Estamos, pues, ante una lucha espiritual contra la revolución social que se avecinaba y que en su componente ideológico se impregna en el esplendor de los viejos mitos y de la cultura heroica de la vieja aristocracia. Se reivindica una tradición que peligra y la cualidad innata de lo noble, de lo que uno porta y lo distingue del resto, junto con la capacidad de valorarlo. Lo interesante es que con esto se reclama también una conducta que vierta en la realidad los ideales ensalzados del viejo mundo. El noble debe serlo en sus maneras. Hay algo eterno, perdurable, en el mundo al que se opone ahora el demos y la poesía lo canta. Así, no es esta una cultura en la que desde dentro se cree un individuo que navega, en ocasiones, contra corriente, sino que por el contrario, se trata de la poderosa atracción de una noble tradición, de un acatar los antiguos valores como mayor proeza pedagógica. Subyace en los poemas de Teognis una melancolía por lo perdido, una nostalgia que trata de responder a la afrenta de la nueva sociedad niveladora, como nivelador es ahora el dinero y rompedor de las antiguas ordenaciones sociales que representaba, en el polo opuesto, la poesía de Solón.

En Píndaro también encontramos las resonancias de lo que se resistía a morir, aunque, creo, con una mayor potencia expresiva y riqueza. "Sus poemas expresan a la perfección y por última vez en la literatura griega la conciencia de clase de la antigua aristocracia griega, la convicción de su propio valor moral y religioso" (Hamilton, 2002, 89). Desde los himnos a los vencedores en las luchas y juegos gimnásticos, se adentra, y esto es lo que lo hace más interesante, en las simas de la existencia. "(...) Píndaro devuelve a la poesía el espíritu heroico, del cual brotó en los tiempos primitivos, y la exalta, por encima de la mera narración de los acaecimientos o de la bella expresión de los propios sentimientos, hasta el elogio de lo ejemplar" (Jaeger, 1990, 200). La mayor manifestación de la areté humana es la victoria. Es decir, la exaltación del vencedor se va sublimando y convirtiendo en la exaltación de un ideal altísimo, en la poesía pindárica, que llegará hasta la filosofía de Platón (Jaeger, 1990, 203). Jaeger emparenta, de hecho, al poeta con el filósofo, como portadores de un mismo espíritu. En este contexto, además, se da en Píndaro, como era propio de la educación aristocrática, una exaltación del pasado. Lo antiguo tiene prestigio y hay que parecerse a ello. La función del poeta será, entonces, elogiarlo, y en esto estriba su potencia y misión educadora. Jaeger trae a colación una evidente sentencia pindárica que sintetiza toda esta ideología: "deviene lo que eres", es decir, deja ser lo que llevas dentro y te constituye (que no suele ser otra cosa que el acatamiento acrítico de la tradición y la clase social que lo constituye hondamente a uno). El poeta señala con su dedo esta atractiva tradición que debe ser respetada y perdurar, la canta en sus versos conmovedores. $Y$ en este dejar ser lo que uno es, la búsqueda y la libertad dadas a una esencia antigua y elevada, es, una vez más, casi Platón, según Jaeger $(1990,207)$. Aunque esto es, claramente, mito, un mito que para el poeta es tan real como la realidad. Un mito que, como una varita mágica, dora y embellece lo que toca, transfigurándolo, dotándolo de una profundidad. Independientemente de las conclusiones del monumental libro de Jaeger, no nos resistimos a anticipar nuestra propia conclusión o presentimiento de que justo esto, 
este elemento mágico, será el que fabrique, ideológicamente, a la universidad, pero, todavía más, a su producto: la ciencia y el pensamiento "independiente" de la nueva clase intelectual que mantendrá bastante de un mundo arcaico de la aristocracia al que, paradójicamente, quiere oponerse a menudo y superar. El problema es si para impugnar un viejo mundo hay que inventar un punto arquimédico en un supuesto o imaginado "exterior", proceso que en mucho imita, inconscientemente, la inercia y admiración hacia el punto exclusivo y privilegiado donde habita el aristócrata y de donde emana todo prestigio social y cultural. ¿Hay, pues, nos enseña la Grecia clásica, una raíz mítica en lo que se muestra y deviene como razón y logos? ¿Hay una base irracional en el devenir de la ciencia y de los científicos? ¿Un eco de la vieja aristocracia en el nous o mente que piensa, que es capaz, de un modo poderoso y omniabarcante, de verlo todo, de ver las esencias, de captar lo que el vulgo no puede captar? Para Píndaro y su mundo, "Sólo entre los nobles existe la sabiduría. Así su poesía es esotérica en el sentido más profundo de la palabra" (Jaeger, 1990, 209). Añade Edith Hamilton: "El poder, sea de la poesía o de cualquier otra cosa, le llega al hombre por nacimiento, no se lo puede enseñar en las escuelas públicas" (Hamilton, 2002, 92). Píndaro nos viene a colación por ser un autor que, aun siendo contemporáneo de la gran revolución democrática, mantiene su mirada en el pasado heroico que él ve trasladado y canta en el mundo del deporte y de los vencedores de los juegos.

\section{Referencias}

Aranguren, J. (2004). La idea de formación, Pensamiento y cultura, 7, 31-46.

Bowra, C. M. (2013). Homero. Madrid: Gredos. Edición original 1972.

Hamilton, E. (2002). El camino de los griegos. Madrid: FCE. Edición original 1930.

Jaeger, W. (1990). Paideia: los ideales de la cultura griega. Madrid: FCE.

Lesky, A. (1970). La tragedia griega. Barcelona: Labor.

Lorite, J. (1985). La "Paideia” en el pensamiento griego. Universitas Philosophica, 3 (5), 81 - 92.

Murray, G. (2013). Esquilo. Madrid: Gredos. Edición original 1940.

Pérez Miranda, I. (2009). Mito, género y paideia. Reflexiones desde la historia antigua, 11, 241-247.

Ramos de Souza, J. M. (2007). A poesia grega como paideía, Príncipios: Revista de filosofía, 14, 21, $195-213$.

Vilanou, C. (2001). De la Bildung a la pedagogía hermenéutica. Ars Brevis, 7, 255-279. 